Journal of Machine Engineering, 2021, Vol. 21, No. 2, 5-23

ISSN 1895-7595 (Print) ISSN 2391-8071 (Online)

Received: 03 March 2021 / Accepted: 28 April 2021 / Published online: 10 June 2021

drilling process, adaptronic spindle, qualitative drill holes

\author{
Alexander DOBRINSKI ${ }^{1 *}$ \\ Hans-Christian MÖHRING ${ }^{1}$ \\ Thomas STEHLE ${ }^{1}$
}

\title{
DEVELOPMENT OF AN ADAPTRONIC SPINDLE FOR A FAULTLESS MACHINING OF HOMOGENEOUS AND INHOMOGENEOUS MATERIALS
}

\begin{abstract}
One of the latest topics in construction concerns the difficulty of producing faultless drill holes in parts made of composite and sandwich materials. At the Institute for Machine Tools of the University of Stuttgart, a prototype of an adaptronic drilling spindle for a machining of components made of homogeneous and inhomogeneous materials was developed within the framework of a research project, funded by the Federal Ministry for Economic Affairs and Energy. The spindle made it possible to limit the axial force and the torque acting on the tool, thus protecting the tools and the workpieces from any possible damage. The tests carried out with the spindle prototype proved that the axial feed force acting from the spindle can be reliably controlled by means of the developed spindle. It might be possible to restrict critical machining situations arising due to the removal of drill chips or the reduction of process temperatures.
\end{abstract}

\section{INTRODUCTION}

One of the latest topics in aircraft and automobile construction concerns the difficulty of producing qualitative drill holes for riveted and threaded joints in high-quality parts made of composite materials, materials on a steel or aluminium basis with pore structure as well as sandwich panels with wave or honeycomb structures. These drill holes have close tolerances and must not show any microdefects such as tool breakage, scratches or tool marks. In the drilling of composite materials, different kinds of manufacturing defects can occur, which may often lead to the failure of valuable workpieces. Approximately $60 \%$ of assembly failures in the aircraft industry are directly connected with damages to the drill hole surface. The most common defects include delamination, fraying, burrs, a thermally overloaded matrix, breakaways and fibre tearing [1].

A low thermal conductivity of the matrix causes thermal overloads in the shear zone between the tool and the drill hole wall during machining. This results in thermal damage, which leads to the softening and the melting of the matrix and thus to the delamination of the material.

\footnotetext{
${ }^{1}$ Institute for Machine Tools (IfW) at the University of Stuttgart, Germany

*E-mail: alexander.dobrinski@ifw.uni-stuttgart.de https://doi.org/10.36897/jme/136277
} 
As a rule, only air is used as a coolant in CFRP machining. The delamination of CFRP materials occurs very often during machining and is directly related to the feed force $F_{f}$ and tool wear. A delamination damage occurs only when $F f$ has reached or exceeded a critical limit. The cutting speed $v_{c}$ is of minor importance here.

Modern manufacturing technology is characterized by a high productivity and machining precision. This leads to a great wear and stress on the machine tool and cutting tool, requiring a variety of process monitoring and safety measures [2]. The tool and workpiece are among the process-relevant objects to be monitored. The aim is to monitor the current course of the machining process, detect irregular process phenomena and avoid machining errors. For this purpose, different monitoring systems were developed to monitor machining processes. These include the intelligent tool holders iTENDO by Schunk and Coromant Capto Plus, which monitors the machining process directly at the tool and enables an adaptive real-time control of speed and feed as well as a tool breakage detection through the use of numerous sensors and complex algorithms, by Sandvik Coromant [3].

To increase the machining quality of components made of composite materials, tool manufacturers offer a wide variety of drilling and milling tools with defined cutting geometry made of coated cemented carbide or polycrystalline diamond (PCD). Qualitative CFRP machining with these tools requires a sharp cutting edge with the smallest possible wedge angle. However, CFRP materials have a high directionally dependent rigidity, and carbon fibres are very hard and highly abrasive, which quickly leads to rounded cutting edges during machining. In the drilling of CFRP, an increasingly rounded cutting edge has a negative effect on the machining quality since it causes delamination, burrs and fraying in the CFRP components.

The potential for optimizing the cutting edge geometry of tools with defined geometry is currently almost exhausted. Therefore, further production possibilities are to be found in order to cover the increasing manufacturing requirements, especially in the automotive and aircraft industry. For example, the active adjustment of cutting parameters (ACP) directly during the cutting process may lead to a significant increase in the effectiveness of the drilling process and thus an improvement in quality.

Experimental investigations proved that the quality of drill holes is not only determined by the tool geometry but also by the cutting parameters and that a correct cutting strategy can have a significant influence on the machining quality [4]. For example, the feed rate or the axial feed force $F f$ determine the delamination size of CFRP at the drill exit. The amount of fraying depends also on the feed force and increases with rising feed values.

The fraying defects are usually distinctive at the entry and exit. Fibre breakage and fibre tearing lead to a reduction in the mechanical properties, e.g. the fatigue limit, of components and occur frequently during the machining of aramid fibre reinforced plastics (AFRP). These defects can be minimized by using circular milling or axial tool movements in drilling. Other defects include burr formation and breakaways. With growing feed rate, the breakaway at the entry and exit of the drill hole increases and thermal material damage occurs [5]. As is generally known, the deformation energy and thus the temperature are mainly within the chip, which can lead to thermal damage of the CFRP matrix (see above) and to a change in the drill hole geometry. In the drilling of CFRP, there are also production problems due to the short life of the cemented carbide tool and the high prices of PCD drills as well as due to the high 
process temperatures and the chip compression in the flutes [6]. The use of hybrid technologies such as ultrasonically assisted machining leads to an increase in the efficiency of CFRP drilling as well [7]. It was found out that ultrasonic drilling reduces cutting forces, torques, the process temperature as well as tool wear and increases machining quality $[8,9]$.

To investigate the potential of the ACP strategy, a research project was conducted at the Institute for Machine Tools of the University of Stuttgart in cooperation with Hugo Reckerth $\mathrm{GmbH}$. This project was funded by the Federal Ministry for Economic Affairs and Energy via the AiF. Its objective was to develop a prototype of an adaptronic drilling spindle for a faultless machining of different homogeneous and inhomogeneous materials such as steel, aluminium, composite materials, glass, cemented carbide, etc. The intention here was that the spindle to be developed should be able to realize the ACP strategy during the machining process by controlling the axial feed force $F f$ acting on the tool during drilling and by automatically limiting the stress on the tool due to the resistance forces and section moduli generated in the shear zone. When a predefined axial force or predefined torque is exceeded, the tool should be shortly withdrawn out of the shear zone. In critical machining phases, e.g. when the drill enters and especially exits the tool as well as at the junction between the material boundaries in stacks and laminates, the axial force and the torque should be adjusted via the control of the linear motor, thus immediately limiting the excessively increased resistance forces. In the phase of high-efficiency drilling, when the tool cutting edge is within the workpiece body and the material removal rate is great, the direction of action of the feed force $F f$ should be controlled in a pulsed manner so that the chip breakage and the chip removal can take place effectively, the temperature in the shear zone drops and the tool cools down. These options can significantly minimize delamination, fraying, burr formation, thermal damages to workpieces and mechanical failure of tools as well as increase the geometrical accuracy and surface quality of the manufactured drill holes.

From an application technology point of view, the adaptronic drilling spindle with drive motor should be mounted on the $Z$-axis of a drilling or milling machine as an autonomous machining unit or should be linked to the machine spindle by means of the hollow shaft taper as a retrofit unit. Hence, the adaptronic drilling spindle with control components should represent a universal drilling system for the qualitative machining of different materials by means of with defined and undefined cutting geometry.

\section{DESIGN AND DEVELOPMENT OF THE DRILLING SPINDLE}

The conducted literature and patent research confirmed the importance of the tasks set and provided necessary information to define the operating parameters for the adaptronic drilling system to be developed. The close cooperation between the project partners enabled a quick definition of the technical parameters relevant for the novel drilling spindle. These included here the diameters of the drilling tools, the necessary spectrum of spindle speed, the required quantity of the axial stroke movements of the tool and the suitable motor spindle variant for the tool drive of the prototype. After the prototype of the adaptronic drilling device was developed, pilot tests for determining the potential of the ACP strategy were carried out with it. 
In the development of the adaptronic drilling spindle, the necessary components of the system were defined first. Several possible concepts of the axial tool drive were compared with each other. Based on the defined requirements, a concept of the adaptronic spindle was created. Figure 1 shows its design principle. The knowledge of the stroke length made it possible to assess the most important parameters of the linear motor. For the axial drive of the tool, a linear motor was developed which was free of hysteresis and could exert a controllable axial force $F f$ on the tool over the entire stroke length. The aim of the first step was to provide the basis for the design of an experimental linear DC motor.

One of the most important parameters was the axial force $F f$ generated by the linear motor. This force $F f$ was used to confirm the functional capability of the tool and was established with the following formula:

where:

$$
F_{f}=B \cdot I \cdot l
$$

$F f$ - effective force on the conductor in the magnetic field,

$B$ - magnetic flux density or magnetic induction in the air gap between the coils,

$I$ - current intensity in the stator coil,

$l$ - length of the electric conductor in the stator coil.

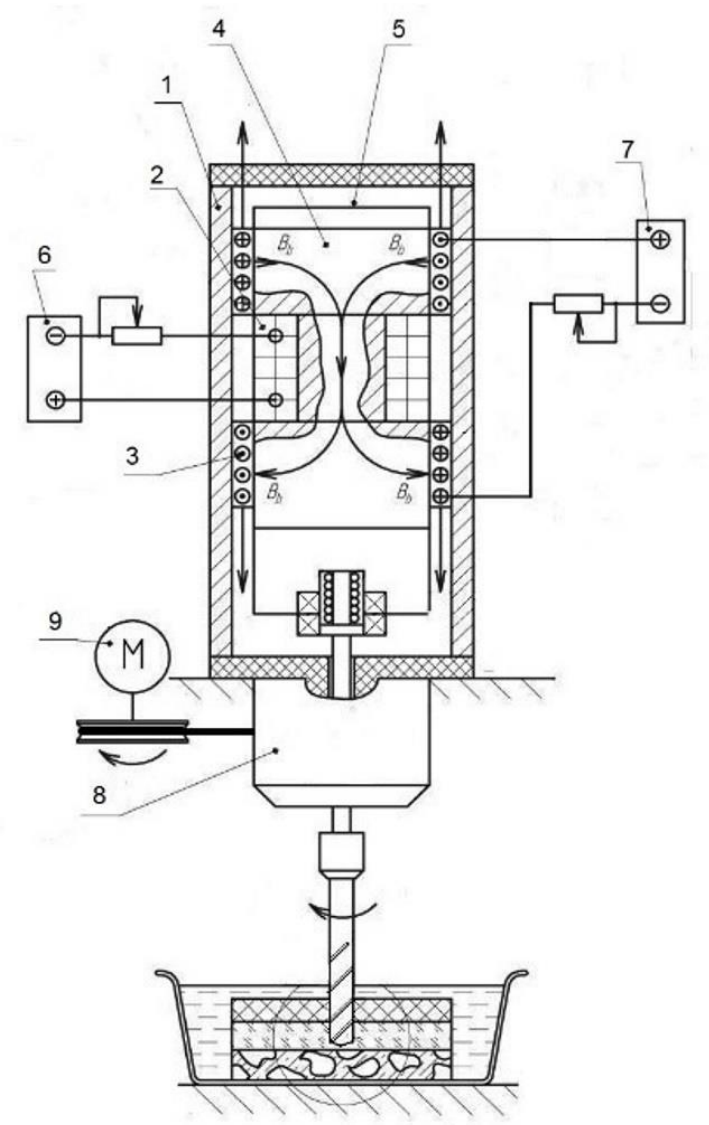

Fig. 1. Components of the adaptronic drilling device:

1 - housing, 2 - stator coil, 3 - rotor coil, 4 - magnetic core, 5 - magnetic conductor, 6 - power supply/stator, 7 - power supply/rotor, 8 - force splitter system, 9 - drive motor of the tool 
In order to define the dimensions of the individual components of the linear motor, a series of tests were carried out with the ANSYS MAXWELL simulation package. The most important components of the motor were modelled, and the design parameters of the magnetic current lines and electric coils were adjusted with regard to the generation of the axial force $F f$. The created simulation models are shown in Fig 2. It was investigated here how the axial force can be influenced by the design of the stator and rotor coils as well as other parameters.

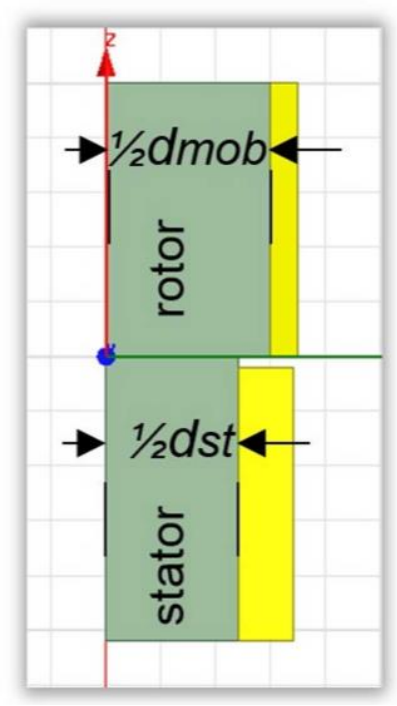

a) $d s t$ / dmob (core diameter) of stator and rotor coils

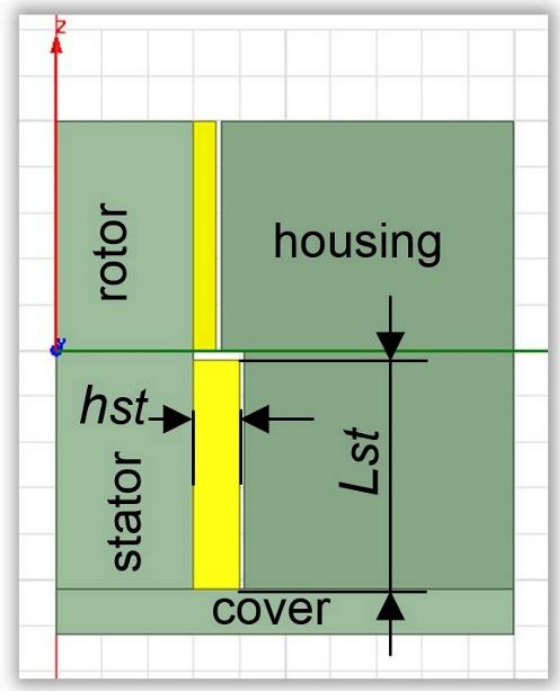

b) „Length / height" of the coil cross-section of the stator coil

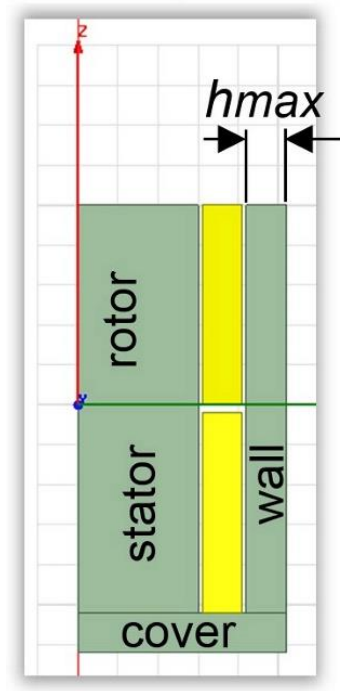

c) Examination of the wall thickness hmax

Fig. 2. Simulation models for the analyses in ANSYS MAXWELL

In the simulation, the following parameters and correlations were identified:

1. The axial force $F f$ of the linear motor depended on the ratio of the stator coil's core diameter $d s t$ to the rotor coil's core diameter $d m o b$. An optimal value $d s t / d m o b$ of the core diameters was defined for the design of the linear motor.

2. The axial force $F f$ had only a minor dependence on the ratio of the stator coil's length Lst to the stator coil's winding thickness $h s t$.

3. The ratio of the coil length to the winding thickness of the rotor coil had a significant effect on the axial force $F f$. The simulation results showed that there is an optimal ratio at which the motor generates the greatest axial force $F_{f}$ (see Fig. 3a).

4. The test showed a strong dependence of the axial force $F f$ on the wall thickness of the linear motor housing (see Fig. 3b)

The analysis of the simulation results showed that the geometry of the linear motor components was relevant for the generated axial force $F f$. The following parameters were particularly important to the design of a functionally capable linear motor: the length and the width of the stator and rotor coils, wire diameter, wire material, the number of windings, housing geometry, the distances between the coils and the housing as well as the moving masses (rotor with drive shaft and tool chuck).

For the development of the linear motor components, the operating temperatures on the coil surfaces in continuous operation were also taken into account. Therefore, the components 
of the linear motor were manufactured out of thermostable materials. As preliminary tests with a model of the linear motor showed, the temperature on the coil surfaces must not exceed $80^{\circ} \mathrm{C}$. For that reason, the linear motor was equipped with a cooling system.

a)

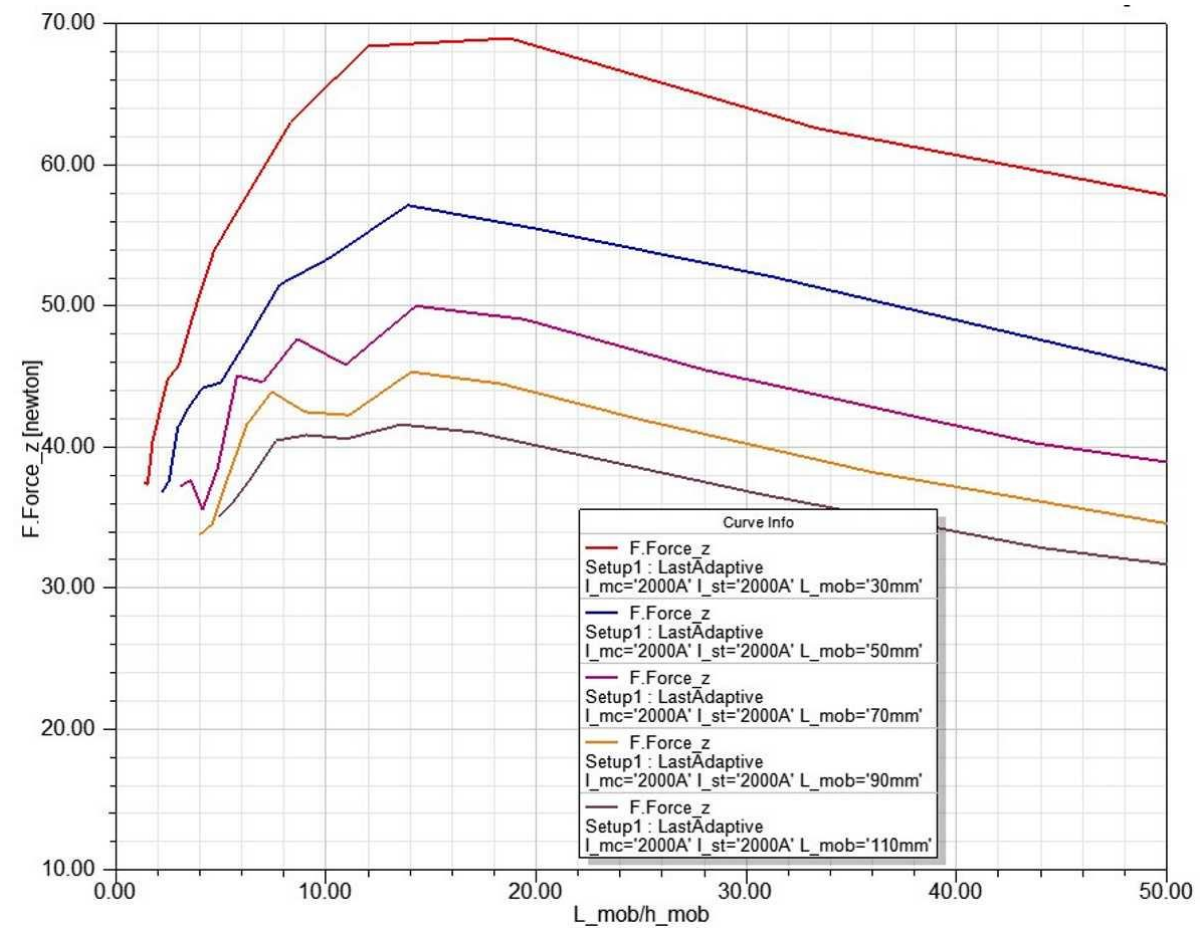

b)

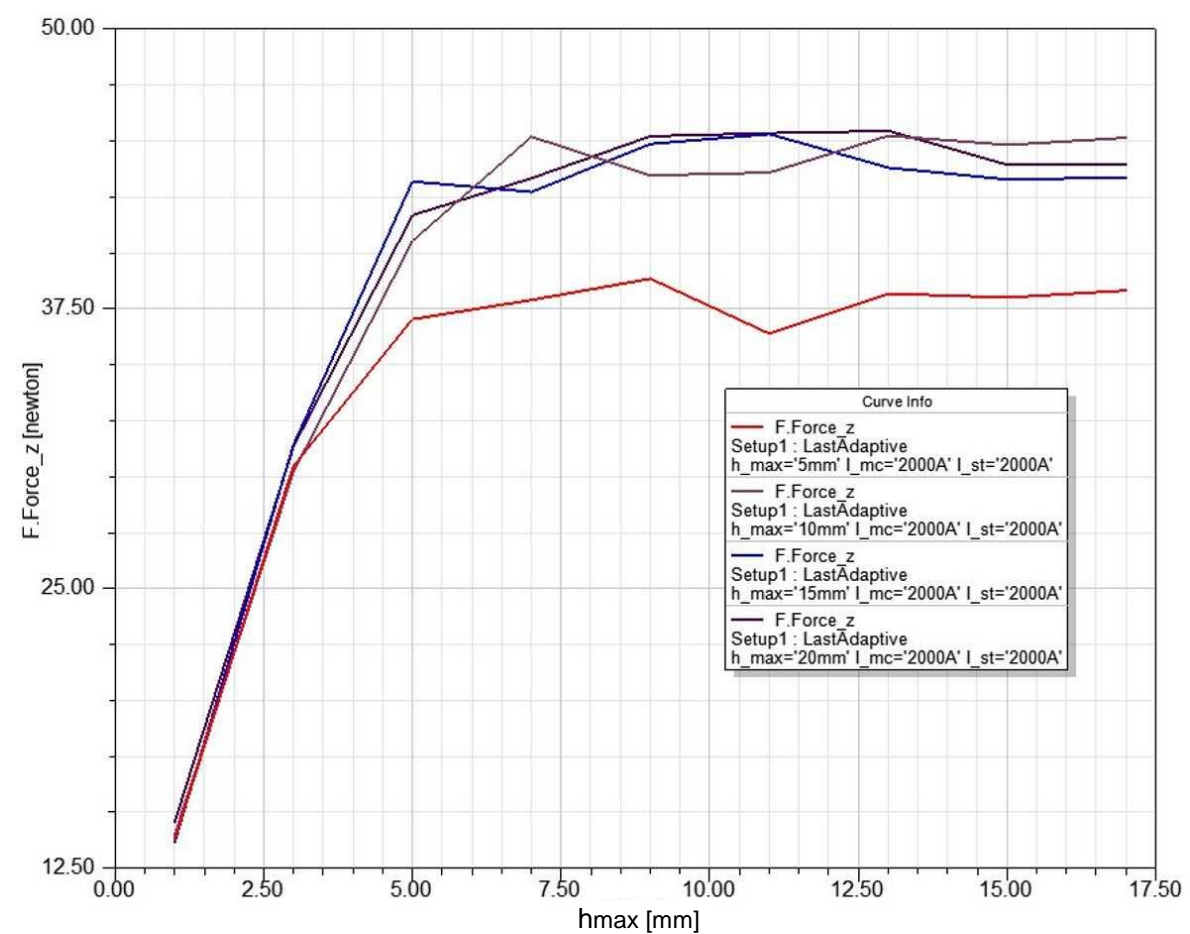

Fig. 3. Results of the simulations concerning the influence of the geometry parameters of the linear motor on the generated axial force $F f:$ a) curve of the axial force $F f$ for varying ratios of the coil length $L \_m o b$ to winding thickness $\left.h \_m o b, b\right)$ curve of the axial force $F f$ for a varying wall thickness $h$ max 
Based on the simulations, a functional model of the linear motor was created. The model consisted of a housing, a stator with a rigid stator coil and a rotor with the rotor coil, which could move axially (see Fig. 4). The characteristics of the electromagnetic field of the stator and the housing were decisive for the working of the linear motor. Therefore, magnetically soft materials were selected for these components. The model of the linear motor was used to check the function capability of the linear motor for the designed adaptronic drilling spindle. The experimental tests of the functional model confirmed the appropriateness of the concept chosen for the linear motor. When the coils were fed with direct current, magnetic fields were generated in the stator and rotor coils and induced electrodynamic and electromagnetic forces. In order to generate the movements of the rotor in both directions, the current value could only be changed in one coil with a control unit. This influenced the force ratio so that the rotor was set in motion. The rotor could generate a translatory motion in both directions with a controlled axial force depending on the current parameter.

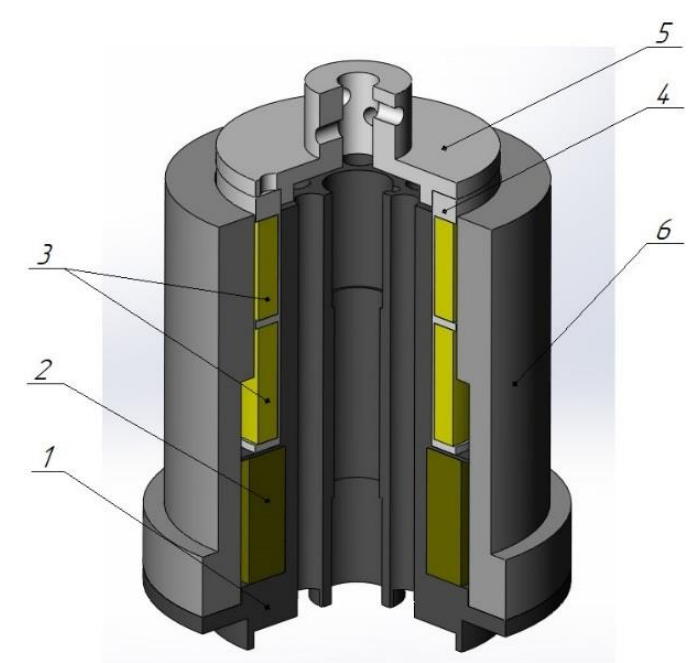

Fig. 4. CAD - functional model of the linear motor for the drilling device: 1 - stator body, 2 - stator coil, 3 - rotor coil, 4 - rotor body, 5 - rotor cover, 6 - housing

In the functional model of the linear motor, the value of the fed current $I$ or the voltage $U$ in the stator coil was controlled. The current value in the rotor coil remained constant here. Thus the translatory motions of the rotor in the specific direction were generated with the desired feed force $F f$ or the axial force $F Z$. In this way, it was possible to adjust the permissible axial force $F Z z u l$ directly during the machining process. An important advantage of this linear motor was that it is not necessary to change the polarity of the coil windings to change the direction of the rotor motion. To change the direction of motion, only the current $I$ in the turns of the stator coil was changed. Such a control system made it possible to apply the axial force $F f$ to the tool exactly and without hysteresis during machining. In addition, the linear motor of the adaptronic spindle was brushless as well as without sparks and friction, making the motor particularly reliable and explosion-proof. One of the most important components of the adaptronic drilling spindle was a mechanical force splitter system, which was used for limiting the maximum torque acting on the drill. The design of the mechanism was backlash-free and allowed immediate removal of the tool from the drilling 
zone when the drilling torque increased. For this purpose, the force splitter performed a vectorial force decomposition of the axial drilling force $F f$ and the drilling torque $M z$, which enabled an immediate reduction in force and torque. The effect of this force splitter was based on the principle of inclined plane. During the drilling process, the force $F f$ generated by the linear motor was transmitted as axial force $F Z$ to the workpiece via the tool and the tool performed the cutting operation with a constant torque $M z$ (from the force $F_{M}$ ) (see Fig. 5). In this case, the resistance force $F Z w$ corresponded to the normal drilling process and the resulting force $F_{T}$ was directed downwards. When the resistance force $F Z w$ or the section modulus $M w$ exceeded a predefined value, the resulting force $F_{T}$ was directed upwards so that the tool moved upwards and out of the shear zone. The resistance force $F Z w$ decreased correspondingly, and the axial force $F z$ reached the predefined value again. The tool moved downwards and came into contact with the workpiece again. This option protects tools and workpieces from breakage or damage, which is particularly common at the drill exit from sheet metal or when drilling materials on a steel or aluminium basis with pore structure as well as sandwich materials with wave and honeycomb structures.
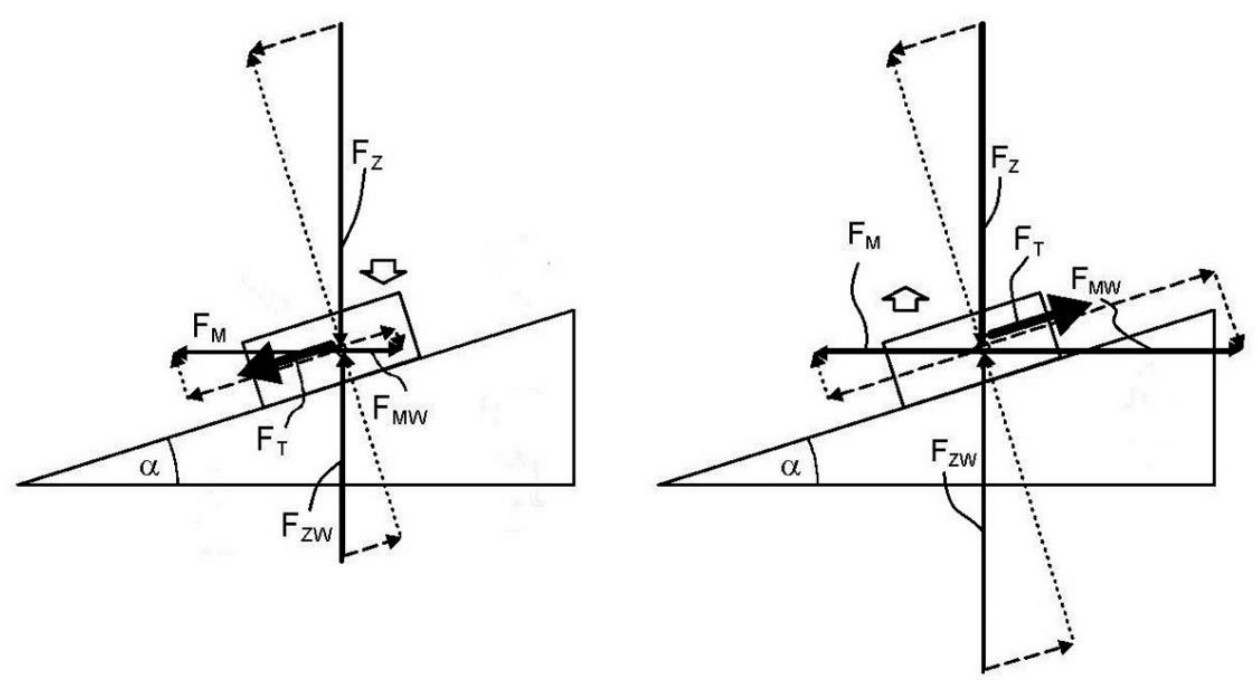

Fig. 5. Operating principle of the force splitter

\section{ANALYSIS OF CONTROL STRATEGIES FOR THE CONTROL SYSTEM THE ADAPTRONIC DRILLING SPINDLE}

In conventional drilling, the feed rate $v f$ remains constant and the feed force $F f$ is the same in all phases of the drilling process, for example, when the tool enters and leaves the workpiece as well as along the entire length of the drill hole. Experience shows that this can lead to the damages to workpiece and tool described above. The developed drilling spindle made it possible to control the feed force $F f$ or the axial force $F z$ during the drilling process depending on the actual tool position and to avoid the above-mentioned damages. Thus, for example, the axial force $F Z$ could be gradually increased or decreased at an unchanged cutting speed $v c$, depending on the achieved tool position or drilling depth, which has 
significant advantages for composite materials. In stack machining, the feed force could be changed depending on the material to be drilled or on the tool position in the drill hole and could be lowered at the tool exit to avoid drill breakage and burr formation.

The developed control system of the drilling spindle could realize these and other machining strategies. The drilling strategies could differ depending on the objective, e.g. a high productivity, a high machining accuracy or a long tool life or rather the prevention of tool breakage. For each objective, a maximum permissible axial force $F Z$ could be defined in advance depending on the application and realized by controlling the current parameters in the coils of the linear motor.

The drilling process with the adaptronic drilling spindle differed significantly from a conventional drilling process. In the conventional drilling process, the drill is inserted into the workpiece with the predefined constant feed rate $v f$ and drilling torque $M z$ or axial drilling force $\mathrm{FZ}$ and these process parameters are not changed until the end of the process. With the developed drilling spindle it is possible to control the axial drilling force $F z$ depending on the axial drill position and the feed rate $v f$ depends on the drilling force. For the case taken into consideration here, the phases of the process had to be defined before the drilling process. First, the tool was put into the starting position at the beginning of the drilling process. For that purpose, only the rotor coil was fed with stabilized direct current, and the rotor coil moved upwards together with the tool shaft under the influence of the electromagnetic force. In the next phase, the current in the stator coil was increased up to a particular value, and the tool moved downwards to the workpiece surface under the influence of the electrodynamic force $F_{e d y n}$. The axial feed force $F_{f}$ had to be minimal here when the tool touches the surface of the workpiece, so that the tool and the workpiece could not be damaged. Then the current values in the field coil were raised for spot drilling. The feed force $F f$ increased, and the tool began to cut. When the drill point had entered the workpiece completely, the axial force $F Z$ could reach the maximum permissible limit. Then the phase of effective drilling began. The tool could carry out the axial motions according to the requirements, the workpiece thickness and the material properties, e.g. in order to remove the chips out of the drill hole as well as cool down tool and workpiece. Close to the drill exit, the axial force must be reduced again. For that purpose, the current values in the stator coil were reduced during the drilling phase and should be adjusted so that the tool could perform axial motions under the influence of the force splitter in the case of a possible increase in resistance force and section modulus. This prevented tool breakage, burr formation and other damaging effects. In order to realize these options of the adaptronic drilling spindle, a computer-aided control system for the linear motor was built.

The linear motor was controlled by changing the current parameters only in the turns of the stator coil. The current values in the rotor coil had to be adjusted in advance and remained constant during the drilling process. The feed force $F f$ and the direction of the axial tool motions were defined by changing the current parameters in the stator coil. The axial position of the tool in the drill hole should be monitored during the drilling process. An inductive sensor in the spindle prototype was used for this purpose. When the tool reached a particular position in the drill hole or nearly broke through the workpiece, the current intensity IStator in the stator coil must be reduced to ensure a smoother drill exit and thus prevent e.g. fraying, delamination, burr formation or tool breakage. 
The adaptronic spindle was controlled by commercially available, programmable laboratory DC power supply units. The power supply unit controlled the linear motor in accordance with the task modelled with the MATLAB environment and based on the initial values of the inductive position sensor. The task of the unit was to control the current value in the windings of the stator coil and to realize the desired operating cycle of the drilling device. The sensor could be used to monitor the tool position in the characteristic drilling phases, such as the spot drilling of the tool into the workpiece, the subsequent effective drilling and the tool exit out of the workpiece body, etc. For each drilling phase, the control of the drilling spindle generated a corresponding separate value of the current intensity IStator. The control chain for this is shown in Fig. 6.

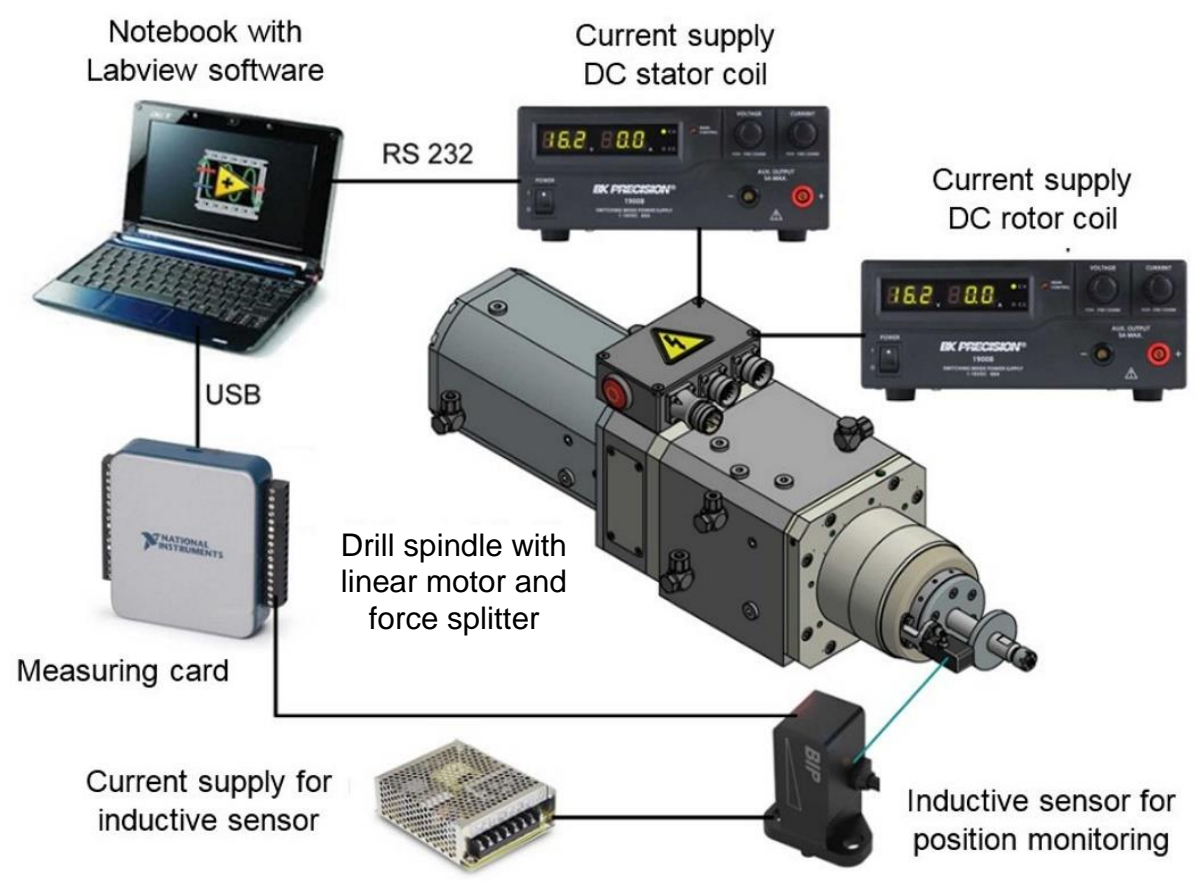

Fig. 6. Control chain of the adaptronic drilling spindle

\section{SIMULATION-AIDED TESTS OF A CHANGE IN FEED RATE TO IMPROVE PROCESS EFFECTIVENESS}

In order to develop the potential of the adaptronic drilling spindle for quality improvement and to test its suitability for the realization of ACP strategies, simulations of a conventional and an interrupted drilling process were performed out with the DEFORM program first, before comparing the results. The drilling process was modelled here for workpieces made of homogeneous materials. For the simulations, several twist drill models were created with different diameters from $1 \mathrm{~mm}$ to $6 \mathrm{~mm}$. Regarding rotational speed and feed rate, typical values for drilling aluminium-silicon alloys were used in order to define the boundary conditions. Table 1 presents the maximum values of the axial forces and the temperatures calculated with DEFORM. 
Table 1. Results of the simulations of a conventional drilling process with DEFORM

\begin{tabular}{|c|c|c|}
\hline Drill diameter & maximum axial force $\mathrm{F}_{\mathrm{z}}$ & max. temperature at the tool \\
\hline $1 \mathrm{~mm}$ & $50 \mathrm{~N}$ & 730 degree \\
\hline $2 \mathrm{~mm}$ & $170 \mathrm{~N}$ & 390 degree \\
\hline $3 \mathrm{~mm}$ & $290 \mathrm{~N}$ & 760 degree \\
\hline $4 \mathrm{~mm}$ & $320 \mathrm{~N}$ & 850 degree \\
\hline $6 \mathrm{~mm}$ & $1000 \mathrm{~N}$ & 870 degree \\
\hline
\end{tabular}

In addition, the simulation results showed that the temperatures at the cutting edge increased up to $870^{\circ} \mathrm{C}$, thus exceeding the melting limit of aluminium. To avoid this, an active adjustment of the cutting parameters could be applied. For example, a short with drawing of the drill by means of an axial tool motion could reduce the cutting temperature during the drilling process. A temperature reduction is also important when machining CFRP, since the high cutting temperatures are often above the melting point of the epoxy resin matrix and thus cause delamination.

For the simulation tests of the drilling process with active adjustment of the cutting parameters, several variants were created for adjusting the feed rate during the drilling process. Using DEFORM, it was analysed how the axial force and the temperature were influenced by varying feed rates. For that purpose, the feed rate of the D3 $\mathrm{mm}$ tool could be given in the preprocessor as a function of time. In the machining with the adaptronic drilling spindle, the feed rate could be controlled by changing the feed force $F f$ and keeping the rotational speed constant at 5,300 rpm. Figure 7 presents the exemplary profile for the feed rate of the drilling tool.

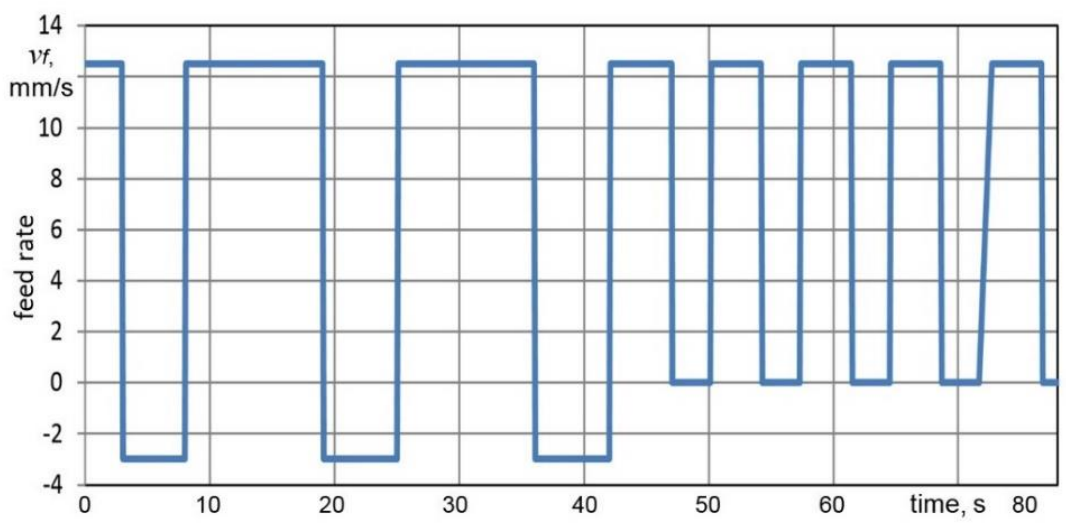

Fig. 7. Exemplary change profile of the tool feed rate with active adjustment of the cutting parameters during the drilling process

The profile shows that there is a maximum feed rate of $v f=12.5 \mathrm{~mm} / \mathrm{sec}$. At the beginning of the process, the drill moved up to the workpiece at a feed rate of $12.5 \mathrm{~mm} / \mathrm{sec}$. After approx. $15 \mathrm{sec}$, the force of the drill decreased as the twist drill lifted off from the point of application. After a pause of $10 \mathrm{sec}$, the tool was moved again towards the workpiece. The feed rate of the tool remained constant here until the deformation at the rear of the workpiece was visible. Then the frequency of the axial feed force variations was raised, and 
the amplitude of the axial tool motions was reduced. A reduction of the temperature in the shear zone was achieved due to the axial tool motions and the short interruptions of the cutting process.

Using the simulations, it was also examined whether the temperature can be reduced by changing the axial feed rate $v f$. The simulation results showed that the temperature of the tool cutting edge at the drill exit could be significantly decreased by adjusting the feed rate (see Fig. 8).

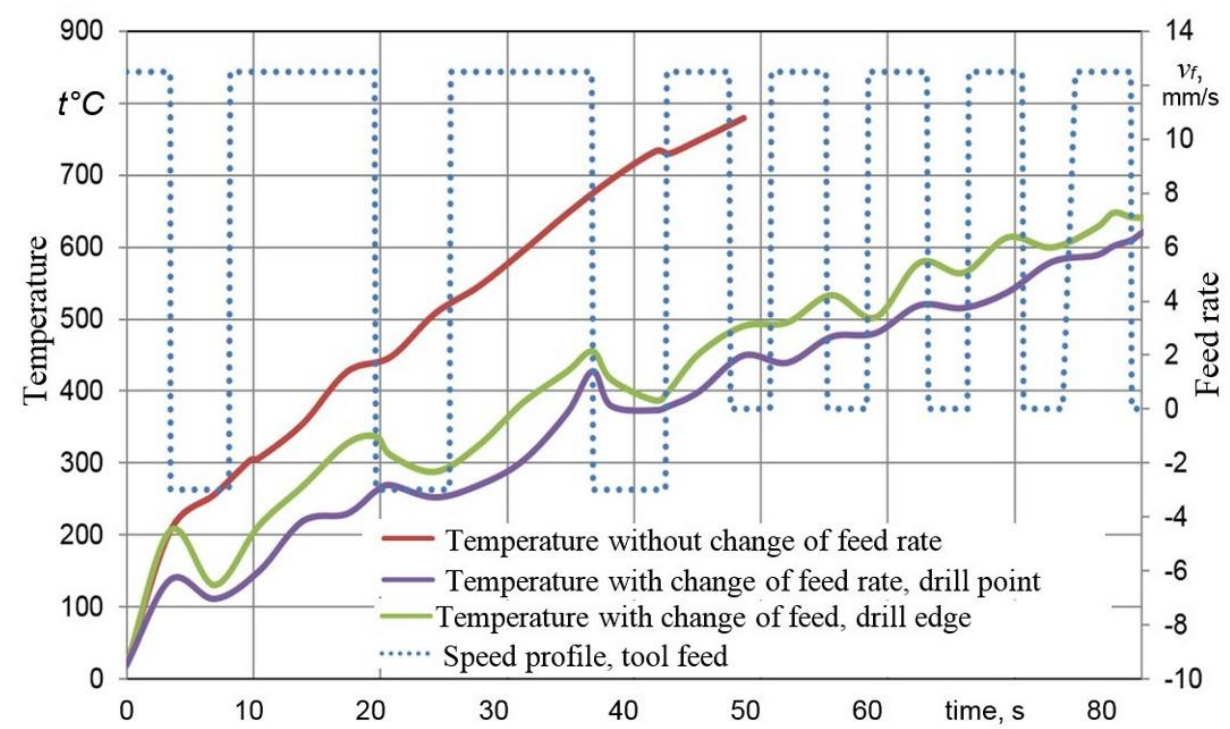

Fig. 8. Comparison of temperature changes in conventional drilling and drilling with active adjustment of cutting parameters

The temperature of the tool rose continuously at constant feed rates. When changing the feed rate $v f$, there was a significant reduction in temperature. At negative feed rates, i.e. at the return stroke of the tool, the temperature reduction was significantly greater because the drill moved out of the shear zone and the chips were removed out of the drill hole. The high temperatures at the rim of the cutting edge had a decisive influence on the typical machining defects in CFRP drilling and were responsible for delamination and melting.

In the temperature diagram, it can be seen that, one the one hand, the temperature during the negative feed decreases significantly and, on the other hand, the maximum temperature at an adapted feed rate is approx. $140^{\circ} \mathrm{C}$ lower compared with the unchanged feed rate. Hence, the simulation results showed that the feed rate strongly influences the temperature of the tool. When the feed rate was negative, the drill moved slightly away from the shear zone and the temperature decreased greatly. In conventional drilling processes, the feed rate was constantly positive, the axial force $\mathrm{FZ}$ remained unchanged and the temperature increased continuously. The maximum temperature could be reduced by $140^{\circ} \mathrm{C}$ from $780^{\circ} \mathrm{C}$ to $640^{\circ} \mathrm{C}$ at partially negative feed rates compared with unchanged drilling processes. The temperatures at the tool point differed on average by about $50^{\circ} \mathrm{C}$ from the temperatures at the tool edge. When the feed rate was varied, the drilling process could take longer because the cutting process was interrupted for a short time and the cutting capacity could be lower. The drilling 
process would take up to $30 \%$ longer with a modelled speed profile. Yet such a production option would involve advantages such as quality assurance, reduction of delamination and burr formation as well as high process reliability, which are often considerably more important, especially when machining high-quality components made of CFRP.

\section{EXPERIMENTAL SET-UP AND EXAMINATION OF THE LINEAR MOTOR}

A universal milling machine was used to carry out the machining tests with the developed prototype of the adaptronic drilling spindle (see Fig. 9). When engineering and designing the developed drilling device, it was intended that drilling processes with different tools, such as HSS and solid carbide drills as well as diamond points with a diameter range between 1 and $6 \mathrm{~mm}$, could be carried out with it. The power supply of the drilling device was realized by means of two commercially available laboratory power supply units with programming function. These power supply units generated the stabilizing direct current and fed both coils of the linear motor, so that it was possible to control the axial feed force $F_{f}$ as well as to axially move the tool shaft in both directions is possible.

The axial force $F z$ and the torque $M z$ occurring during the drilling tests were measured with a dynamometer by Kistler, Type 9273, which was mounted on the worktable of the milling machine. Two charge amplifiers were connected via the existing outputs of the dynamometer. The values of the axial force $F Z$ and the torque $M Z$ were transmitted via a shielded Kistler 1677A5 connection cable to the measuring card, where they were processed and forwarded to the computer. The measuring system is shown in Fig. 10.

The experimental tests of the linear motor were aimed at determining the achievable values of the axial forces $F Z$ at different axial tool positions as well as the corresponding values of the direct current in the stator and rotor coils. The temperature on the coil surfaces was also controlled in the tests. The cooling system of the adaptronic drilling spindle served for stabilizing the operating temperatures of the motor spindle and the linear motor. A compact cooling unit was used to cool the drive spindle and the linear motor.

The tests with the prototype linear motor were carried out varying the electric parameters. The achievable values of the axial force $F Z$ in both directions of motion were established here depending on the current intensity $I$ and the voltage $U$ of the direct current in both coils of the linear motor. The force values were measured for different distances between the two coils of the linear motor in order to determine the achievable axial force at different stroke positions of the rotor or tool positions.

In addition to the axial force measurements, the temperatures on the coil surfaces were also controlled. Based on the results obtained, the parameters of both electric coils of the linear motor were adjusted specifically, including length, width, wall thickness, wire diameter and wire length. Furthermore, the effective values of the direct current for driving the linear motor were established here as well.

Figures 11 and 12 illustrate exemplary measurement curves of the axial forces $\mathrm{FZ}$ developed by the linear motor when changing the tool position, the current power in the stator coil and the current $I$ in the stator coil. 
The conducted tests with the linear motor showed good results. The results and development experience gained here will be applied to future designs of the linear motor in subsequent development phases as well as to series designs of the adaptronic drilling spindle.
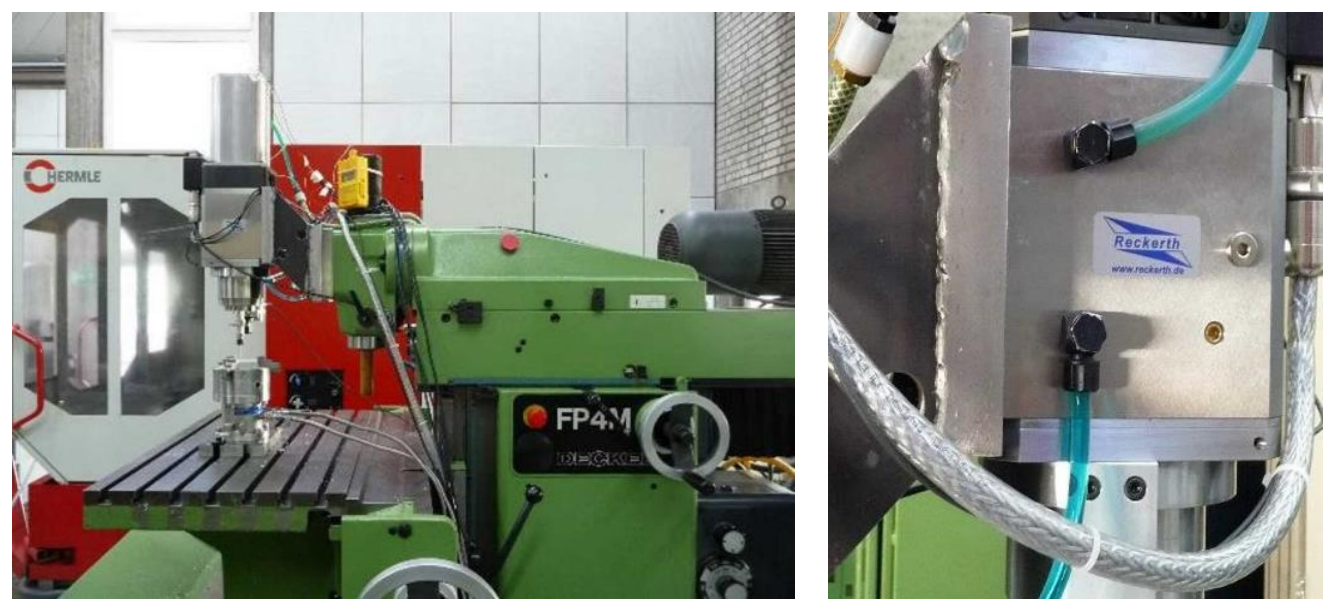

Fig. 9. Test setup with the prototype of the adaptronic spindle in the IfW test field

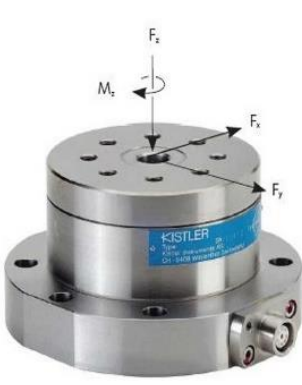

a

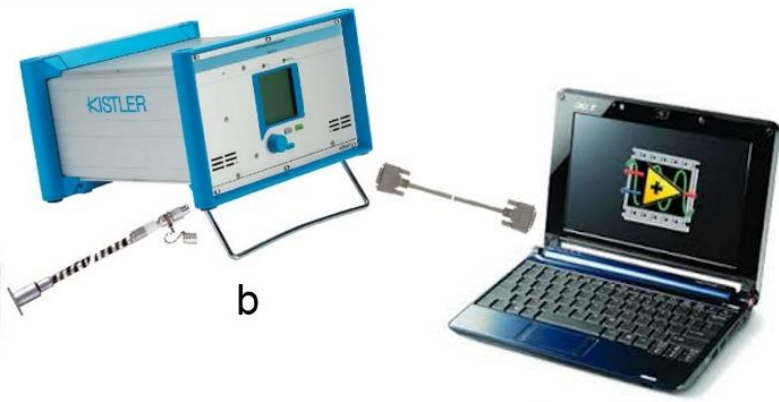

C

Fig. 10. Measuring chain for recording the curves of feed force $F Z$ and torque $M Z$ during drilling: a) Kistler Type 9272 dynamometer, b) Kistler Type 5070A amplifier, c) laptop with NI LabView and cables for transmitting measurement signals

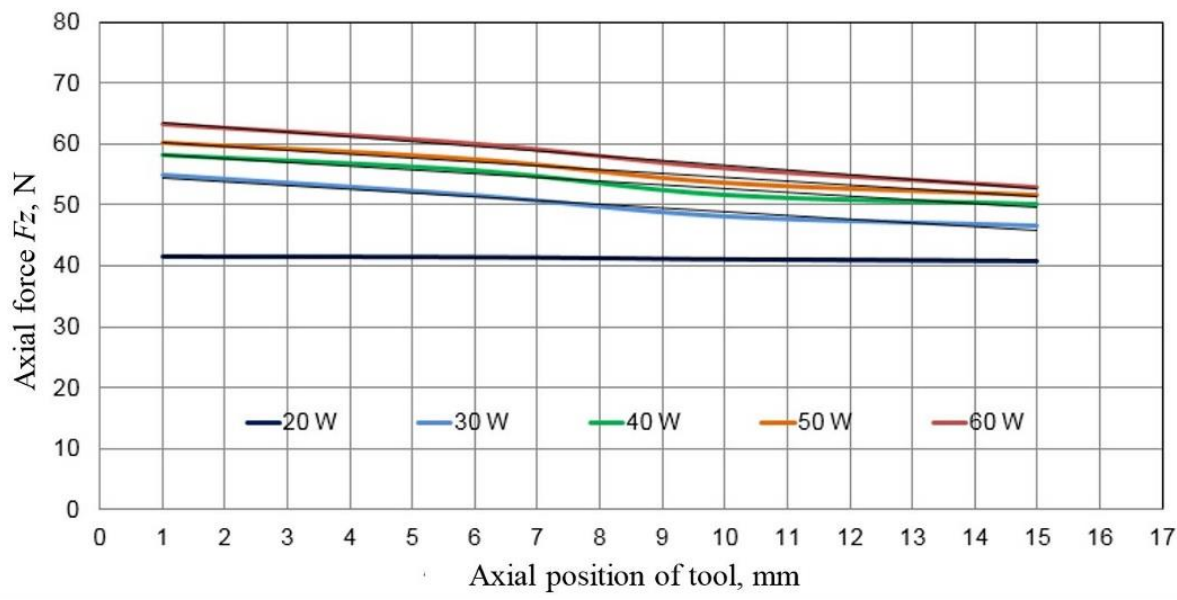

Fig. 11. Axial force $F Z$ developed by the linear motor when changing the tool position and the current power in the stator coil 


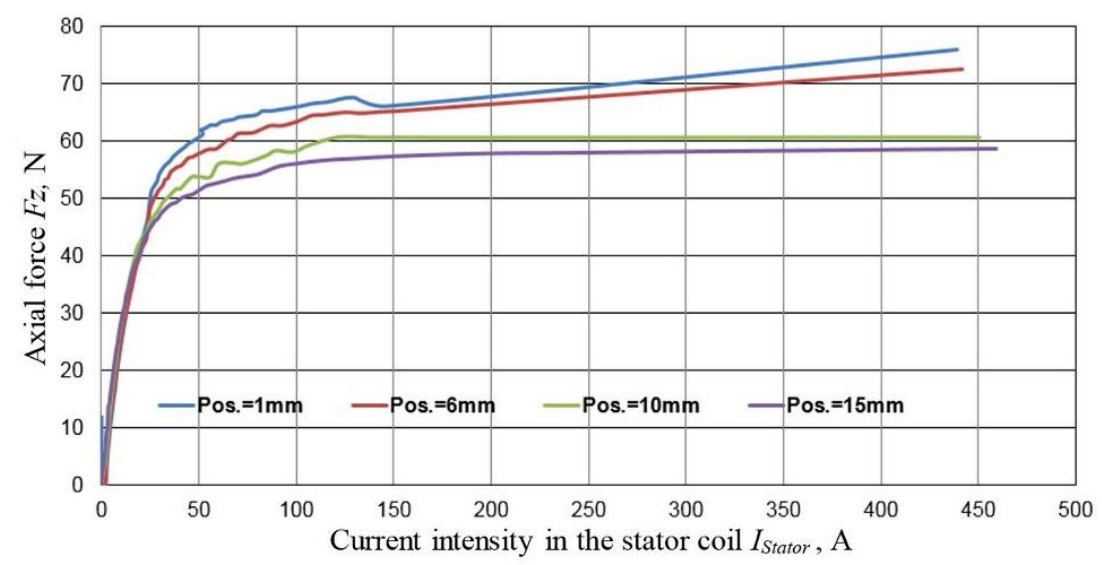

Fig. 12. Axial force $F Z$ developed by the linear motor when changing the tool position and in the stator coil of current $I$

\section{EXPERIMENTAL TESTS OF THE SPINDLE PROTOTYPE AND DISCUSSION OF RESULTS}

The experimental tests of the spindle prototype were aimed at examining the functional capability of the entire design concept. Solid carbide and HSS twist drills according to DIN 338 as well as diamond grinding mounted points D126 and CBN grinding mounted points B126 with diameters from 1 to $6 \mathrm{~mm}$ were used for the tests. The cutting speed $v c$ or the tool speed $\mathrm{n}$ was defined as a function of the respective tool diameter and the type of material. The pilot tests were carried out with semi-finished products made of different materials (steel, titan, aluminium, CFRP, GRP, honeycomb, glass, cemented carbide, etc., see Fig. 13).
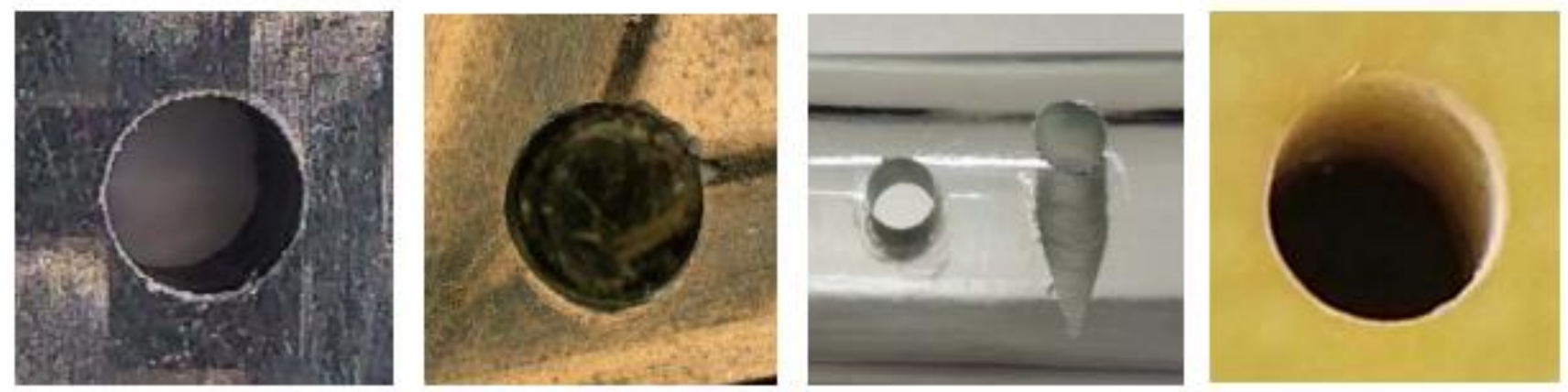

Fig. 13. Test drilling in semi-finished products made of different materials (CFRP, cemented carbide, glass, GRP)

The values of the maximum permissible drilling force $F Z$ were used for the tools between 1 to $3 \mathrm{~mm}$ from the simulation results with DEFORM. For the tools with diameters between 4 to $6 \mathrm{~mm}$, the maximum achievable for the spindle prototype $F Z$-force values were applied. In serval series of tests, the workpieces were fixed and drilled at angles between $45^{\circ}$ 
and $85^{\circ}$ to the spindle axis. During the machining tests with the spindle prototype, the $F Z$ values were varied and adjusted with regard to drilling quality and process stability. The effective torques and axial forces were established with the built measuring system.

It was found out in the tests that the values of the feed force $F f$ ranging between "-" 60 $\mathrm{N}$ (the tool lifts off the workpiece) and " + " $80 \mathrm{~N}$ (the tool penetrates the workpiece) could be safely changed and reliably controlled in real time via current parameters in the coils of the linear motor. The drilling process with the developed spindle prototype differed significantly from a conventional drilling process. In this way, it was possible, for example, to define and determine the different phases of the drilling process. The axial force $F Z$ could be reliably controlled within the range from 0 to $80 \mathrm{~N}$ along the stroke length of the developed linear motor during the drilling process (see Fig.14, left). The tool shaft of the drilling spindle could move axially in both directions to remove the chips and cool the shear zone. By varying the current values in the stator coil, it was possible to change the parameters of the magnetic field, which led to a change in the axial force $F Z$ acting on the tool. The "sensitivity" of the force splitter could be varied by adjusting the specified axial force $F z$. This option allowed the force splitter to work effectively in a wide range of drilling torques. For that reason, the drilling tools with different diameters were able to perform axial movements even with a small increase in drilling force or torque above the predefined value, e.g. due to the material inhomogeneity or chip compression. The task of the force splitter system was to prevent tool breakage, burr formation and the negative effects of the drill exit. For example, when machining thin-walled parts made of sheet metal, there is often an effect of screwing-in at the drill exit, which leads to a sudden increase in the section modulus and axial force. It can lead to tool breakage and/or damage to the workpiece.

The adaptronic spindle enabled drilling processes even if the workpiece surface is at an angle of up to $60^{\circ}$ to the tool axis of rotation (see Fig. 14, right). The combined effect of the controlled axial feed force and the force splitter enabled a gentle tool entry on the workpiece surface. For that purpose, the value of the axial feed force $F f$ should be 5 to $10 \mathrm{~N}$ when the tool touches the workpiece surface. After the drill point entered the workpiece, the feed force might be increased up to the maximum value without damaging the tool or the workpiece. It was also found that the gentle tool entry made it possible to easily drill a thin bridge of approx. 2-3 $\mathrm{mm}$ between two adjacent holes without a deviation in the tool axis and without damaging the tool. This option could also be carried out safely when the workpiece was inclined. In addition, a series of drilling tests was successfully carried out with flat and round-shaped glass workpieces by positioning the workpieces perpendicularly and obliquely to the tool axis (see Fig.13). The adaptronic drilling spindle produced here blind and through holes faultlessly without glass breakaways and crack formation. Diamond and CBN tools were used in these tests.

The examinations into the production parameters of the spindle prototype were carried out to a limited extent and revealed the necessity of further improvements. In order to fully develop the potential of the adaptronic drilling spindle, further design and control measures are still to be carried out. These include, for example, the radial stiffness of the bearing of the axially movable tool shaft, the increase of the axial feed force $F f$ generated by the linear motor and the development of a programmable system to control the feed force depending on the tool position. 
The maximum axial force $\mathrm{Fz}$ developed by the linear motor could be up to $100 \mathrm{~N}$ depending on the current value in the motor coils. However, the temperature of the linear motor increased rapidly at force values over $80 \mathrm{~N}$. Preliminary tests of the prototype showed that the current values required for a continuous operation in the rotor coil should be up to $5 \mathrm{~A}$. The current values in the stator coil could be varied within the range from 0 to $10 \mathrm{~A}$ in order to enable an efficient control of the axial force $F z$.

To remove the chips out of the drill hole and to cool down the tool, the direction of action of the axial force or rather the direction of movement of the tool shaft could be changed by controlling the current parameters in the stator coil. This option could also be used for chip breakage. The experimental tests with the spindle prototype (see Fig. 14) confirmed the effect and functional capability of the developed force splitter system. Its design proved to be robust as well as reliable and it could operate in a wide range of rotational speeds from 0 to $15,000 \mathrm{rpm}$, effectively limiting the section modulus torque $M w$ acting during the drilling process. It can be regarded as further proof of the resolving effect that no drill was broken in the machining tests carried out with varying tool diameters under different operating conditions.
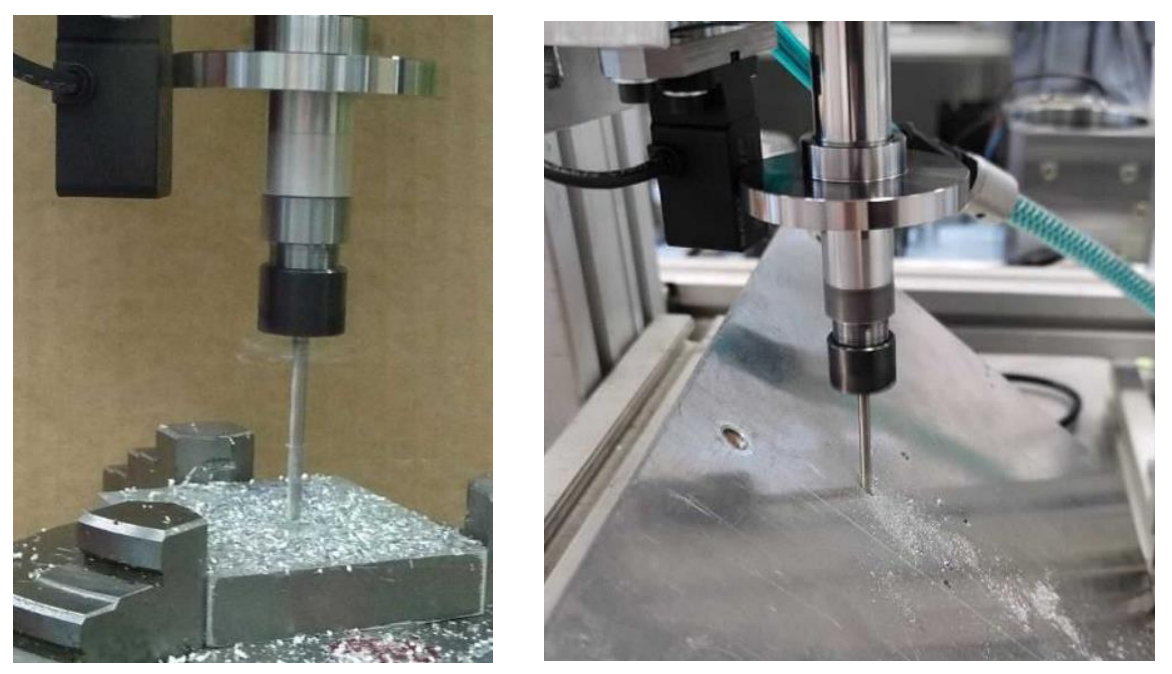

Fig. 14. Drilling process with the developed adaptronic spindle: shaft of spindle prototype with collet chuck and drilling tool as well as sensor of position measuring system at workpiece entry (left) and when drilling inclined workpieces (right)

The feed force values $F f$ achieved with the test prototype were reproducible and were always identical to the corresponding current parameters in the two coils of the linear motor (see Fig. 15). During the tests, the amount of axial drilling force $\mathrm{FZ}$ was controlled by changing the current parameters in the stator coil via a simple programme. The changes in drilling force here followed at regular time intervals. If required, the current values and time intervals could be varied flexibly. Under production conditions, the control of the axial force $\mathrm{FZ}$ depends on the axial tool position, which is recorded via the position sensor. This possibility has already been realized with a programme in the MATLAB language and is being tested at the IfW for its practical suitability. The operating temperature at the two coil surfaces did not exceed the limit of $70^{\circ} \mathrm{C}$. 


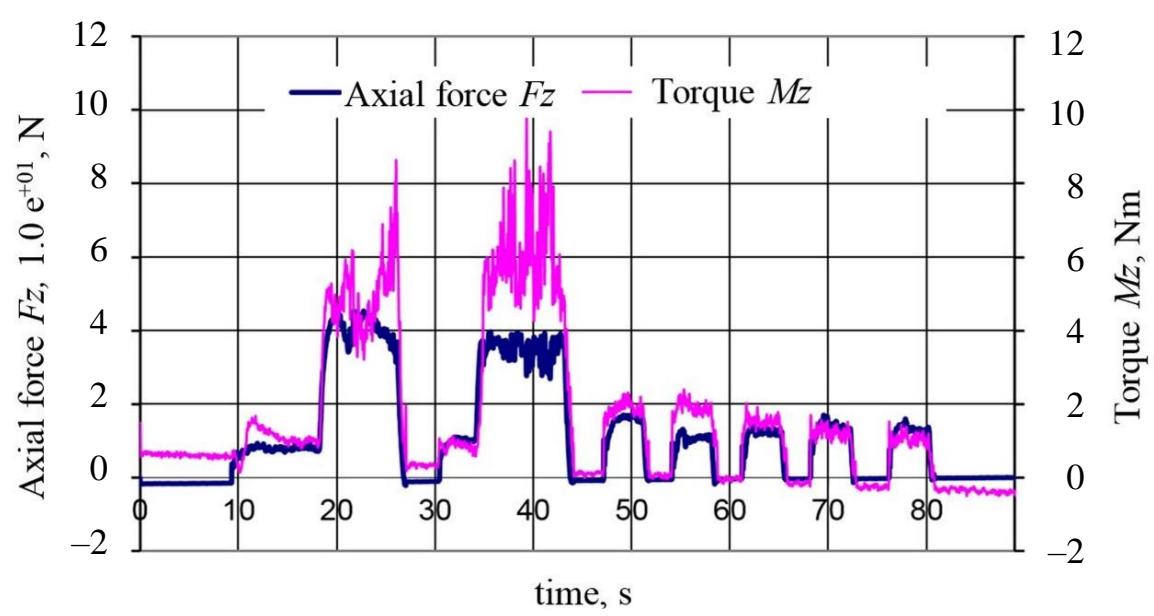

Fig. 15. Axial force $F z$ and torque $M z$ during drilling of the Alu-Si alloy with the programmed control of the current value in the stator coil (test tool with $3 \mathrm{~mm}$ diameter)

Thus a high repetition rate could be guaranteed for the axial force values $F Z$ and torques $M Z$ during the experiments with the test prototype. Homogeneous aluminium was used as the workpiece material for the machining tests measuring drilling force $F Z$ and drilling torque $M Z$. This allowed the controlled change of the drilling force $F Z$ to be established without the influence of workpiece-related irregularities.

\section{CONCLUSION AND OUTLOOK}

After the analysis of possible concepts for the adaptronic drilling spindle, the components of the linear motor were developed and produced together with those of the force splitter system or rather the device for limiting axial force and torque. It was investigated which characteristics the hysteresis-free linear motor must have for performing feed motions with a defined axial feed force $F Z$. With the built prototype of the linear motor or rather the adaptronic drilling spindle, experimental tests were carried out regarding the achievable axial forces for varying current parameters in the coils of the linear motor. These tests proved the functionality of the adaptronic drilling spindle. The force splitter system of the adaptronic drilling spindle automatically monitored the axial force $F Z w$ acting on the tool and the section modulus $M w$ during the machining process. When a critical torque value was exceeded, the drilling spindle briefly lifted the drill and then lowered it to penetrate the workpiece again. In this way, it was possible to specifically control the feed force and limit the axial force $F Z$ and the torque $M z$ acting on the drill. In addition, the developed adaptronic drilling could prevent the drill from being deflected from the centre of the axis and thus from being centred. Furthermore, an excessive warming of the component as well as the tool cutting edge and thus an overheating of the material could be avoided by using the developed drilling spindle. Hence, the developed drilling spindle enables qualitative and faultless drilling processes of various materials. In further project steps, the production characteristics of the adaptronic drilling spindle will be specifically investigated for different materials. 


\section{ACKNOWLEDGEMENTS}

The ZIM project "Development of an adaptronic spindle for the qualitative and faultless drilling of fibre reinforced plastics and hybrid materials" was funded by the Federal Ministry for Economic Affairs and Energy via the AiF. The authors would also like to thank the cooperating industry partner for their effective support of this research. Especially to be mentioned here is the management of Hugo Reckerth GmbH for supporting the design, the production of components as well as the assembly and the adjustment of the innovative adaptronic drilling spindle.

\section{REFERENCES}

[1] PFEIFROTH T., 2014, Beitrag zur Verbesserung der spanenden Bohrbearbeitung von CFK auf Basis von Schädigungsmechanismen, Dissertation, IfW, Universität Stuttgart.

[2] WECK M., BRECHER C., 2006, Prozessüberwachung, Prozessregelung, Diagnose und Instandhaltungsmaßnahmen, Werkzeugmaschinen, 3, VDI-Buch, Springer Vieweg, Berlin, Heidelberg, DOI: 10.1007/978-3-540-325 06-2_6.

[3] mav Innovationsforum März, 2019, www.mav-online.de.

[4] BIERMANN D., RAUTERT C., BATHE T., 2014, Bohrschleifen von CFK mit unterschiedlichen Bindungsmatrizes, Diamant Hochleistungswerkzeuge, 3, 36-41.

[5] SULTANA I., SHI Z., ATTIA M.H., THOMSON V., 2016, Surface Integrity of Holes Machined by Orbital Drilling of Composites with Single layer Diamond Tools, Elsevier, Procedia CIRP, 45, 23-26.

[6] BIERMANN D., RAUTERT C., NIEMANN M., BATHE T., 2013, Pecking-Verfahren bietet Potenziale im Leichtbau, WB Werkstatt + Betrieb, 3, 56-59.

[7] LAUWERS B., 2011, Surface Integrity in Hybrid Machining Processes, Procedia Engineering, 19, $241-251$.

[8] FLEISCHER J., TETI R., LANZA G., MATIVENGA P., MÖHRING H.-C., CAGGIANO A., 2018, Composite Materials Parts Manufacturing, CIRP Annals - Manufacturing Technology, 67/2, 603-626.

[9] LI Y., REN C., WANG H., HU Y., NING F., WANG X., CONG W., 2019, Edge Surface Grinding of CFRP Composites Using Rotary Ultrasonic Machining: Comparison of Two Machining Methods, The Int. Journal of Advanced Manufacturing Technology, 100, 3237-3248. 